\title{
Notas sobre o ensino da filosofia na Universidade de São Paulo: sujeição e resistência
}

\author{
Notes on the Teaching of Philosophy at the University of São Paulo: subjection and \\ resistance
}

\section{José Roberto Sanabria de Aleluia}

Doutorando na Universidade Estadual Paulista Júlio de Mesquita Filho, Marília, São Paulo, Brasil. sanabria@hotmail.com.br

ORCID: https://orcid.org/0000-0001-6587-1374

Recebido em 30 de agosto de 2019

Aprovado em 28 de novembro de 2019

Publicado em 07 de janeiro de 2020

RESUMO:Almejamos através da presente investigação analisar a constituição discursiva sobre a formação filosófica uspiana com intuito de compreender quais foram as condições que permitiram a emergência dos saberes e poderes que sustentaram os objetos de conhecimento no ensino de Filosofia na Faculdade de Filosofia, Ciências e Letras da Universidade de São Paulo (FFCL-USP), observando o período de formação (constituição) do curso de filosofia que se estende de 1936 até 1963. A pesquisa utiliza como referencial teórico-metodológico a arqueologia do pensador francês Michel Foucault, na qual o sujeito é fundamentalmente uma produção das práticas discursivas e de relações de saber-poder que o atravessam e o delimitam. Por meio deste procedimento metodológico pretendemos entender a emergência dos modos de subjetivação e objetivação e fornecer visibilidade não só às grandes linhas de continuidade discursiva, mas também das descontinuidades que abrigam os vestígios e arquivos submersos da história oficial. Palavras-chave:Filosofia; Ensino de Filosofia; Arqueologia; Universidade.

ABSTRACT: Through this research we aim to analyze the discursive constitution about the Uspian philosophical formation in order to understand what conditions allowed the emergence of knowledge and powers that supported the objects of knowledge in the teaching of Philosophy at the Faculty of Philosophy, Sciences and Letters of the University of São Paulo (FFCL-USP). For this purpose, we observed the period of formation (constitution) of the Philosophy course from 1936 to 1963 . The research uses as theoretical-methodological reference the archeology of the French thinker Michel Foucault, in which the subject is fundamentally a production of discursive practices and knowledgepower relations that go through and delimit him. With this methodological procedure we intend to understand the emergence of modes of subjectivation and objectification and provide visibility not only to the great lines of discursive continuity, but also to the discontinuities that shelter the submerged traces and archives of the official history. Keywords: Philosophy; Teaching of Philosophy; Archeology; University. 


\section{Introdução}

Em 1970 os brasileiros Sergio Paulo Rouanet e José Guilherme Merquior duelaram contra o filósofo Michel Foucault em uma épica entrevista ${ }^{1}$. O combate se desenvolveu em vírgulas paulatinas que enunciam o gran finale: uma especulação. Merquior ao questionar o niilista de cátedra sobre o assunto principal de sua aula inaugural no Collège de France se deparou com uma confissão. Foucault afirmou que pretendia ministrar um curso sobre as noções teóricas do seu último livro A arqueologia do Saber (2012), contudo revelou estar embaraçado por não possuir um objeto definido em seu discurso, pois contemplava naquele instante o paradoxo de uma aula inaugural. O impasse encontrava-se no rito de passagem, especificamente no desconforto intransmissível de assumir o lugar do seu mestre Jean Hyppolite. Para Foucault naquele instante as malhas do poder e sua complexidade de resistir a institucionalização do discurso são reveladas, pois o que precede a palavra inaudita ressoava na solenidade ordem, assim as inquietações que aspiravam ao ato de falar foram tensionadas pelo desejo de escapar dos lugares que honram o discurso, mas os desarma.

São surpreendentes e singulares as palavras que Foucault elaborou frente aos questionamentos de Merquior, na medida em que comparamos com o discurso enunciado semanas depois no Collège de France. A dissonância materializada no livro A Ordem do discurso: aula inaugural no Collége de France - pronunciado em 02 de dezembro de 1970, indicam uma problematização da positividade dos saberes e poderes na constituição da subjetividade moderna. Logo, a singularidade dos enunciados foucaultianos nesse período emerge como possibilidade de pensarmos as relações de poder e as práticas de ensino da filosofia através das relações de forças existentes entre os sujeitos e ordens discursivas instituídas no processo de ensino e aprendizagem filosóficos.

Dito isto, o presente artigo tem por objetivo analisar como os processos de subjetivação que desenharam-se no curso de Filosofia da Faculdade de Filosofia, Ciências e Letras na Universidade de São Paulo (FFCL-USP)². A partir dos referenciais teóricos elaborados por Michel Foucault nas obras A arqueologia do saber (2012) e A ordem do discurso (1996), organizamos nossa análise e exposição em três momentos. O primeiro pretende situar o projeto filosófico-propedêutico elaborado por Jean Maugüé através do texto O ensino de Filosofia: suas diretrizes (1955) e verificar se há alguma proximidade com a abordagem metodológica desenvolvida pelo professor francês Victor Goldschmidt no artigo e Tempo histórico e tempo lógico na interpretação dos sistemas filosóficos (1963). Como sabemos, os dois artigos representam o ponto alto da reflexão crítica que articulava simultaneamente um "conjunto de reflexões sobre o específico da história da filosofia e sua inseparabilidade do discurso filosófico, entremeado com uma crítica historiográficometodológica e metodológico-filosófica da história da filosofia" (MARQUES, 2013, p. 84).

Diante dos elementos enunciado acima, o segundo momento, tem por finalidade entender as consequências do modelo uspiano de pensar a Filosofia nos processos de formação filosóficos e de pensar a função ocupada pelo ensino da Filosofia nesse modelo. 
Por fim, vamos nos apoiar nas noções foucaultianas de sujeição, subjetivação e resistência, para compreender melhor o lugar do ensino da Filosofia. Entendemos que a noção de subjetivação manifesta nas análises realizadas por Foucault, considera-a como um processo que se constitui nas relações de poder, ou seja, um processo que se estabelece na tensão entre o movimento de dominação e de resistência. Assim, procuraremos pensar de que modo e como os mecanismos de poder produzem estratégias de sujeição no ensino da Filosofia e quais as possibilidades de resistência a esses movimentos.

\section{Ensino da filosofia: notas arqueológicas}

Em abril de 1969 a entrevista concedida por Michel Foucault a revista Magazine littéraire $n^{\circ} 28$, tinha a intenção de explicitar ao público francês A arqueologia do saber, especificamente demonstrar como Foucault formulou os procedimentos metodológicos sintetizado naquela complexa obra.

Diante tarefa de alcançar argumentos claros sobre uma obra metodológica de difícil acesso, o entrevistador J. J. Brochier perguntou a Foucault: "Você intitulou seu livro de A arqueologia do saber. Por que arqueologia?” (FOUCAULT, 2001, p. 145). Foucault, na pretensão de ser o mais claro e conciso afirmou que isso ocorreu por duas razões.

Inicialmente, empreguei essa palavra de maneira um pouco cega,
para designar uma forma de análise que não seria efetivamente uma
história (no sentido em que se relata, por exemplo, a história das
invenções ou das ideias), e que tampouco seria uma epistemologia,
ou seja, a análise interna da estrutura de uma ciência. Trata-se
de uma coisa diferente, e então eu chamei de "arqueologia";
depois, retrospectivamente, pareceu-me que o acaso não tinha
me guiado muito mal: afinal, essa palavra "arqueologia" ao preço
de uma aproximação que me será perdoada, eu espero, pode
querer dizer: descrição do arquivo. (FOUCAULT, 2001, p. 145).

Como podemos observar, a constituição desse procedimento metodológico vincula-se diretamente com percepção investigativa caracterizada pelo autor como descrição do arquivo. Para Foucault (2001, p. 145), arquivo é o conjunto de discursos efetivamente pronunciados, ou seja conjuntos de discursos que "teriam ocorrido uma vez por todas e que permaneceriam em suspenso, nos limbos ou no purgatório da história, mas também como um conjunto que continua a funcionar, a se transformar através da história, possibilitando o surgimento de outros discursos".

Se arquivo equivale ao conjunto de discursos pronunciados, seria possível pensar uma unidade do discurso como ocorre na ciência? Segundo Machado (2006) como que os discursos são abordados em um nível anterior a classificação dos tipos, logo Foucault rejeita as categorias aceitas tradicionalmente e formula quatro hipóteses com a finalidade de compreender a unidade discursiva. Vejamos quais são as hipóteses definidas por Foucault (2012, p. 36-40): 
$1^{\text {a) }}$ os enunciados, diferentes em sua forma, dispersos no tempo, formam um conjunto quando se referem a um único e mesmo objeto; $2^{\mathrm{a}}$ ) para definir um grupo de relações entre enunciados deve-se levarem conta sua forma e seu tipo de encadeamento; $3^{a}$ ) não se poderia estabelecer grupos de enunciados determinandoIhes o sistema de conceitos permanentes e coerentes que aí se encontram em jogo? $4^{a}$ ) a identidade e a persistência dos temas podem relacionar os enunciados de uma mesma formação discursiva.

Como sabemos essas quatro hipóteses foucaultianas não foram elaboras com intuído de pensar o ensino da Filosofia, mas com a finalidade de compreender as formações discursivas que estabeleceram unidades discursivas sobre temas como loucura, medicina e as ciências humanas. Contudo, acreditamos ser possível pensar com Foucault o ensino da Filosofia uspiano pelo viés arqueológico para compreendermos de que modo o discurso sobre esse tema se constituiu na Universidade de São Paulo.

Para isso, analisaremos os textos de Jean Maugüé $O$ ensino de Filosofia: suas diretrizes (1955) e de Victor Goldschmidt Tempo histórico e tempo lógico na interpretação dos sistemas filosóficos (1963). Entendemos que esses dois textos têm a função de arquivo, principalmente porque os discursos reais efetivamente pronunciados, que foram estudados e se efetivaram na prática corrente na tradição que pretendemos compreender.

Machado (2006, p. 153), procurando explicitar a noção de discurso em Foucault, afirma que "discurso é um conjunto de regras dado como sistema de relações. Essas relações constituem o discurso em seu volume próprio, em sua espessura, isso é, caracterizam-no como prática". Sendo assim é possível compreender os textos que adotamos como arquivo (conjunto de discursos pronunciados), pois constituem práticas discursivas determinadas no tempo e no espaço e que definiram as condições de existência da função enunciativa uspiana. Diante disso almejamos analisar a partir das concepções de arquivo e discurso como o ensino da Filosofia foi pensados nesses dois textos enquanto uma unidade discursiva.

\section{Maugué e o nascimento de uma certidão}

O filósofo Jean Maugüé publicou no Anuário da Faculdade de Filosofia, Ciências e Letras da Universidade de São Paulo em 1937, uma síntese "na forma escolar de diretrizes para o ensino da Filosofia, um documento capital para o entendimento do rumo ulterior dos estudos filosóficos uspianos, a bem dizer sua certidão de nascimento" (ARANTES, 1994, p.63).

Lavrado com o nome de O Ensino da Filosofia: suas diretrizes, o artigo almejava "fixar as condições de ensino filosófico na Faculdade de Filosofia Ciências e Letras da Universidade de S. Paulo" (MAUGÜÉ, 1955, p.642). Resultado das aproximações e dos traços que Maugüé elaborou após um ano de convívio com a cultura brasileira (refém do autodidatismo filosófico e da imigração das doutrinas estrangeiras). As diretrizes estabelecem condições 
didáticas de ensino, através de um programa de estudo histórico-filosófico que emerge como descontinuidade discursiva ${ }^{3}$ e modifica as práticas educacionais e a rotina de estudos da primeira geração de intelectuais uspianos.

O procedimento adotado para análise deste documento se baseia nos procedimentos arqueológicos, neste termos a descrição dos enunciados seria o passo mais sensato para compreender a ordem discursiva sobre o ensino da Filosofia. Assim, o procedimento adotado busca descrever a "função enunciativa de que são portadores, analisar as condições nas quais se exerce essa função, percorrer os diferentes domínios que ela pressupõe e a maneira pela qual se articulam é tentar revelar o que se poderá individualizar como formação discursiva" (FOUCAULT, 2012, p. 142).

Diante disso o artigo que analisaremos deve ser pensado através dos enunciados como função que se apoia em um conjunto de signos, que para se realizar requer um referencial4, um sujeito5, um campo associado6 e uma materialidade7, logo nossa orientação de análise seguirá as condições impostas pela descrição enunciativa. Feita as devidas observações procedimentais metodológicas cabe analisarmos o objeto em questão.

No primeiro parágrafo de suas diretrizes Maugüé (1955, p. 644) resume as condições do ensino da Filosofia na seguinte fórmula: a "Filosofia não se ensina. Ensina-se a filosofar"8. É curioso notar que apropriação feita por Maugüé da filosofia kantiana resulta de uma concepção filosófica paradoxal, pois se aceitarmos a fórmula como verdadeira é preciso admitir que não há um corpo de verdades já constituídas, ou seja precisamos assumir que a inexistência de um organon filosófico que possa se apresentar como uma tábula de conteúdo a ser apreendido. Segundo Maugüé (1955, p. 644) a Filosofia não possui objeto próprio.

Fácil é compreender que a filosofia [...] não pode apresentar-se como um conjunto de conhecimentos objetivamente transmissível. A sua sorte está ligada aos encaminhamentos, às vicissitudes, ao progresso das atividades cientificas, morais e estéticas sobre as quais ela medita.

É possível observar as implicações inerentes à filiação do pensamento de Maugüé a filosofia kantiana, especificamente como sua concepção epistêmica e histórica9 conduz a argumentação para impossibilidade do ensinar a Filosofia, enfatizando apenas a possibilidade do ensino do filosofar.

Essa impossibilidade ocorre porque a Filosofia, diferentemente da Ciência, não possui um objeto transmissível ou um conjunto de verdades determinadas. Ela é a própria atividade racional. "A filosofia é reflexiva. É o espírito ou a inteligência que se apreende a si mesma" (MAUGÜÉ, 1955, p. 643).Sendo assim, seria impossível ensinar a Filosofia para alguém após adquirir esses conhecimentos e praticar tal atividade. Nesses termos, nenhum professor teria condição de manipular as estruturas cognitivas dos sujeitos aprendizes de tal modo a incutir neles uma prática filosófica. Cordeiro (2008, p. 86), analisando tais relações afirma que: 
Há, segundo Maugüé, um caráter dialético envolvido na arquitetura do problema. Pensamento, ensino e formação são constituídos e se constituem mutuamente, estão em relação de interdependência, as vias que os interligam são de mão dupla. Tanto a Filosofia é o filósofo quanto o filósofo passa a ser a Filosofia apresentada.

Esse princípio de identidade elaborado por Maugüé, na qual o saber (Filosofia) constitui o sujeito (filósofo), assim como, o sujeito (filósofo) constitui o saber (Filosofia) oferece as primeiras evidências e possibilidades para compreendermos os processos de subjetivação existente nos práticas do ensino da Filosofia. Para Maugüé (1955, p. 645), a "filosofia é, pois, comunicável como é comunicável um sentimento. Max Scheler lembra a velha identidade da dialética da inteligência e da dialética do amor. Muito longe está a filosofia de ser uma 'matéria' que se ensine". Ora se a incomunicabilidade do sentimento equivale à incomunicabilidade da Filosofia, a incomunicabilidade do ensino da Filosofia será a condição do filósofo-professor, pois o que Ihe sobrará será apenas o ensino do Filosofar.

Essa condição leva-nos a alguns enunciados curiosos, como por exemplo: o "filósofo é um espírito que trabalha diante de outros espíritos, sendo que, deste modo, tudo depende do filósofo" (MAUGÜÉ, 1955, p. 645). Para o autor como não existem conteúdos para o ensino da Filosofia o filosofar depende da paixão e da inteligência do filósofo-professor, assim o espírito do estudante será lapidado conforme os conteúdos adquiridos pelo mestre e sua paixão por esses conteúdos. Consequentemente nos perguntamos: qual é objeto segundo as diretrizes maugüetiana do ensino da Filosofia? Uma possível resposta pode ser encontrada nas seguintes palavras de Maugüé (1955, p. 647).

Parece-nos que a tarefa do professor de filosofia, no Brasil, consiste em não esquecer as ideias novas, mas principalmente em situá-las lealmente, modestamente, no conjunto da perspectiva filosófica. É preciso não ter medo de passar por "clássicos", ou por "elementar"... É preciso que nos recusemos esse prazer de parecer renovadores de ser ultra modernos... O que é necessário é suscitar, avivar no estudante o senso da reflexão e das ideias gerais: em suma, criar o discernimento.

Analisando com cuidado as palavras do autor encontramos indícios de um objeto, isso porque se admitirmos que o professor de Filosofia é a própria Filosofia e, que essa Filosofia não pode ser transmitida por conteúdos determinados, pois é a pura reflexão desse professor-filósofo, necessariamente teremos que assumir a relação saber/sujeito. Frente a essas proposições é possível inferir que a reflexão sobre saberes precedentes (conhecimento científico, estético, moral e filosófico) será imperativo na constituição da subjetividade do professor. Esse sujeito (professor-filósofo) tem como tarefa situar saberes novos no rol das perspectivas filosóficas clássicas, com o objetivo de produzir no estudante o senso da reflexão e discernimento. Assim, entre a tarefa e objetivo, emerge o objeto que seria o próprio Filosofar. Para o autor filosofar "é entrar em contacto com essa 
atividade, é traçar a sua orientação, é tornar a achar a inteligência, o espírito, nos domínios de seu exercício e mesmo nos resultados dos seus esforços" (MAUGÜÉ, 1955, p. 643).

O filosofar emerge como objeto do ensino da Filosofia não porque existe uma unidade discursiva, mas porque a dispersão enunciativa de diversos saberes inundam o cotidiano da FFLC-USP em seus primeiros anos de existência. Segundo Maugüé (1955, p. 647) nestes "últimos cinquenta anos temos visto desfilar muitas 'marcas' filosóficas, o behaviorismo, o gestaltismo, a fenomenologia, a caracteriologia, o freudismo. Representam elas níveis muito desiguais de valor e madureza intelectual". Consequentemente, quando o professor-filósofo cataloga inúmeros saberes e relaciona com a História da Filosofia, trabalha para que o discernimento desejado ocorra no aluno aprendiz. Para o autor (1955, 645) o "ensino da filosofia deverá ser, pois, principalmente histórico. Será a seguir, mais seguramente contemporâneo". O discernimento produzido no aluno decorrerá do seu conhecimento da História da Filosofia que irá auxiliá-lo na compreensão do presente.

Ainda segundo Maugüé (1955, p. 648) a "filosofia começa com o conhecimento dos clássicos. A História da filosofia deve ter, no Brasil, um lugar primordial. Ela pode ser ensinada, seguindo métodos rigorosos e perfeitamente modernos". A forma e o encadeamento dos enunciados elaborados por Maugüé produziu um estilo, assim ensinar Filosofia no Brasil só poderia ocorrer mediante a História da Filosofia, essa forma de ensino da Filosofia tem por fundamento, especificamente a leitura dos clássicos.

\section{Goldschmidt: corolário de uma continuidade}

O filósofo Victor Goldschmidt nunca foi professor na Universidade de São Paulo, porém como afirma Cordeiro (2008, p. 154), do filósofo da Université de Rennes "foi professor de vários dos professores e pesquisadores provenientes do Departamento de Filosofia da USP e que constituíram a nova feição filosófica da Universidade". Como sabemos alguns goldschmidtianos incentivaram a disseminação da leitura do texto filosófico pelo método estrutural em território brasileiro. Um dos principais representantes do estruturalismo goldschmidtiano foi seu ex-aluno Oswaldo Porchat Pereira. O filósofo paulista foi o responsável pela tradução para o português de um pequeno texto publicado como como apêndice no livro A Religião de Platão chamado Tempo histórico e tempo lógico a interpretação dos sistemas filosóficos (196). Para Cordeiro (2008, p. 154) o texto de Victor Goldschmidt solidificou, "o processo de marcha dos estudos filosóficos na USP no sentido do nosso ingresso no concerto filosófico das nações". Essa indica uma clara unidade discursiva entre os enunciados de Maugüé e Goldschmidt, mas qual o ponto de articulação entre esses dois discursos? Segundo Porchat Pereira (2010 p. 20):

\footnotetext{
Nesse trabalho de refazer os movimentos filosóficos que estruturam uma filosofia particular, de apreender sua lógica interna, impõe-se seguramente a necessidade metodológica de deixar de lado as posições pessoais, os pontos de vista filosóficos que eventualmente se tenham, faz-se mister o esquecimento metodológico de si próprio. E se trata, por certo, de um método difícil de se praticar.
} 
O discurso acima refere-se a reflexão que Porchat compartilhou com os estudantes de Filosofia da USP sobre pesquisa em Filosofia, em 18 de maio de 1998. Suas palavras descrevem bem como o método estrutural de Goldschmidt foi recebido no departamento da FFLC-USP. Essa pretensa continuidade, que busca constituir uma formação discursiva aproximando a proposta maugüetiana ao método de Goldschmidt, tem seu fundamento na identidade e na persistência dos temas, especificamente na crença de uma evolução da proposta de Maugüé contida no rigor das análises dos sistemas filosóficos pelo estruturalismo goldschmidtianos.

Para Goldschmidt (1963) existem duas maneiras de interpretar um sistema, através dos métodos dogmático e genético; o primeiro é considerado filosófico, pois ao examinar a verdade de um sistema subtrai-o ao tempo; o segundo é considerado científico devido seu caráter instrutivo e contrariando o primeiro método, não subtrai-o ao tempo, pois defende a evolução dos sistemas. Ainda segundo o autor (1963, p.140):

\begin{abstract}
A filosofia é explicitação e discurso. Ela se explicita em movimentos sucessivos, no curso dos quais produz, abandona e ultrapassa teses ligadas umas às outras numa ordem por razões. A progressão (método) desses movimentos dá à obra escrita sua estrutura e efetua-se num tempo lógico. A interpretação consistirá em reaprender, conforme à intenção do autor, essa ordem por razões e em jamais separar as teses dos movimentos que as produziram.
\end{abstract}

Essa definição de Filosofia como explicitação e discurso foi considerada pela tradição uspiana a evolução do estilo maugüetiano, pois o filósofo-pesquisador munido do método dogmático poderia interpretar as estruturas dos pensamentos filosóficos reaprendendo através da intenção dos Filósofos (Platão, Descartes, Kant, etc.) as razões e o próprio movimento que as produziram. De acordo com Porchat Pereira (2010, P. 19) a tradição uspiana foi formada "na sólida tradição historiográfica francesa e que sua influência sobre nós foi extraordinariamente importante, particularmente sob a forma do assim chamado método estruturalista de leitura e estudo das obras filosóficas". O desenvolvimento da tradição se forjou através da recepção das diretrizes maugüetiana pelo método estrutural. Vejamos um dos pontos angulares dessa unidade discursiva:

O ensino - e aqui ele escapa completamente ao professor - será, não apenas histórico mas sobretudo pessoal e íntimo. Um estudante apenas pode considerar-se no caminho da filosofia no dia, mas só no dia em que, no silêncio do seu quarto de estudo, começar a meditar por si mesmo sobre algum trecho de um grande filósofo (MAUGÜÉ, 1955 p, 646).

Como podemos observar nas palavras de Maugüé, dois elementos são fundamentais: o sujeito (estudante) e o saber (texto filosófico). O sujeito é entendido aqui como um ser autônomo, pois alcançará o estatuto de filósofo quando diante dos textos clássicos (Platão, Tomás de Aquino, Descartes, Espinosa, etc.) aprender a filosofar. Essa estrutura discursiva 
será recebida pelo método estruturalista sem ruído aparente, pois a estrutura de qualquer texto filosófico é fundamentado em um tempo lógico. Sobre esse tempo explica Goldschmidt (1963, p.144) utilizando como exemplo a obra Meditações Metafísicas de Descartes.

\begin{abstract}
Esse tempo, sem dúvida, varia segundo o leitor; ele dura "alguns meses" ou "algumas semanas". Mas a estrutura das Meditações é dada objetivamente, o método que a submete tem pretensões a um valor universal, e o tempo onde se desenvolve esse método é um tempo lógico, apreendido pelo leitor-filósofo, ainda que esse leitor, se ele se chame Pedro, possa gastar com isso menos tempo físico que se ele se chama Paulo. [...] toda filosofia é uma totalidade, onde se juntam, indissoluvelmente, as teses e os movimentos. Esses movimentos, efetuando-se num tempo lógico, implicam memória e previsão; mesmo se eles se apresentam como rupturas, são feitos com conhecimento de causa; são decisões ("batalhas", dizia Descartes); o que, ao mesmo tempo, mede a coerência de um sistema e seu acordo com o real, não é o princípio de não contradição, mas a responsabilidade filosófica.
\end{abstract}

Essa é a ordem discursiva que desde 1963 ronda as instituições educacionais brasileiras, em particular a USP, sendo sustentada pelo modelo propedêutico-metodológico composto pela História da Filosofia (Maugüé) e pelo estruturalismo francês (Goldschmidt). Contudo, vale ressaltar que no processo de unidade discursiva toda potencialidade das diretrizes maugüetianas foi suprimida pela leitura e explicitação das estruturas lógicas do texto filosófico. "Como vemos", afirma Cordeiro (2008, p.165) "Guéroult e Goldschmidt complementam a missão de Maugüé, porém no nível metodológico, uma vez que a plataforma da nova geração já estava implantada e formava seus primeiros quadros".

Apresentada as balizas da formação discursiva uspiana e descrita a continuidade entre os enunciado de Maugüé e Goldschmidt através de um panorama arqueológico, resta finalmente compreender o processo de subjetivação nas práticas discursivas uspiana.

\title{
Processo de subjetivção: sujeição e resistência
}

A noção de processo de subjetivação presente no pensamento de Foucault10 pode a figurar-se como um importante instrumento conceitual para compreendermos as relações discursivas que habitaram na constituição do espaço e do ensino da Filosofia da FFLC-USP. O modo como o processo de subjetivação pode desenhar-se possibilita como as relações de saberpoder e dominação se estabelecem no regime discursivo sobre a formação filosófica brasileira.

Foucault não tem como tema central em sua obra o problema da Educação ou do ensino da Filosofia, porém, faz um questionamento muito interessante na aula inaugural proferida no Collège de France em 1970.

O que é, no fim de contas, um sistema de ensino senão uma ritualização da fala, senão uma qualificação e uma fixação dos papéis dos sujeitos falantes; senão a constituição de um grupo doutrinal, por difuso que 
Para Foucault o ensino também faz parte daquilo que chama de grandes procedimentos de sujeição do discurso que visam a manutenção desse mesmo discurso. Amparando o discurso existe um regime de verdade que da sustentação a ele.

A educação pode muito bem ser, de direito, o instrumento graças
ao qual todo o indivíduo, numa sociedade como a nossa, pode ter
acesso a qualquer tipo de discurso; sabemos no entanto que, na sua
distribuição, naquilo que permite e naquilo que impede, ela segue as
linhas que são marcadas pelas distâncias, pelas oposições e pelas
lutas sociais. Todo o sistema de educação é uma maneira política de
manter ou de modificar a apropriação dos discursos, com os saberes
e os poderes que estes trazem consigo. (FOUCAULT, 1996, p.43).

A partir das reflexões foucaultianas podemos nos perguntar: o que sustenta o discurso no e sobre o ensino da filosofia na USP? É possível dizer que também no ensino da filosofia existe um regime de verdade que dá amparo ao discurso do professorfilósofo. Nesse regime discursivo em que o professor e estudante têm cada um seu papel específico, pode ser percebido nitidamente o exercício do poder que percorre a relação de ensino/aprendizagem. De um lado está o professor, detentor do saber Filosofia, que procura inscrever por meio da disciplinarização do saber aquele que precisa ser inscrito no mesmo regime discursivo de que é devedor, um modo de compreender a Filosofia.

Sendo assim é possível afirmar que o ensino da Filosofia pensado na FFLC-USP a partir de Maugüé e Goldschmidt se fundamenta em um regime de verdade que dá sustentação ao discurso do professor e, simultaneamente sujeita-o ao discurso determinado do que deve ou não ser ensinado para que o aluno ingresse nesse regime de verdade do qual o professor é guardião e anunciador. Uma das funções do ensino da Filosofia é fazer com que o aluno entre no regime discursivo, que permite que ele faz seja direcionado em um modo específico de compreender a Filosofia. Tal modelo de pensamento apóia-se na crença da necessidade de formatar a reflexão do aluno para que abandone a maneira corriqueira (senso comum) de pensar e assim alcançar um discernimento crítico localizado e amparado na tradição filosófica. Cria-se com isso um ritual iniciático ao pensamento filosófico. Para Cordeiro (2008, p.161-162)

[...] até hoje as recomendações, e considerações de Goldschmidt orientam as novas gerações no árduo e indispensável exercício formativo que a leitura estrutural dos clássicos fornece e são exigência de primeira ordem em grande parte dos departamentos brasileiros de Filosofia.

O rito inicial afetou os corpos dos estudantes de filosofia na FFLC-USP, quiçá em todo Brasil, isso se pensarmos replicação formativa nos quadros de professores da maioria 
dos departamentos de Filosofia, que apreenderam diretamente ou indiretamente o ritual uspiano. Interessa-nos compreender os dois lados dessa relação, que poderíamos chamar também de pólos de força, no ensino da Filosofia: o discurso do professor, que funciona como disciplinador do saber a ser adquirido pelos alunos. Nessa relação se produzem modos de sujeição resultantes dos jogos de força imanentes ao processo de ensino/aprendizagem.

Por outro lado, no entanto, notamos que nem todos os alunos se enquadram nesse regime discursivo, ou seja, muitas vezes os alunos produzem uma diferença nesse processo que é entendida como uma anomalia, uma vez que não repetem (não fazem a recognição) daquilo que foi ensinado. A nosso ver, o processo de subjetivação nos alunos se expressa de dois modos: de sujeição ao poder exercido pelo professor e de resistência a esse exercício quando o aluno não se submete a ele.

Obviamente que não se pode afirma a existência apenas de alunos que são resistentes e subjugados, ou seja não se encontra alunos plenamente resistentes ou plenamente sujeitados, mas momentos de sujeição e momentos de resistência no processo de subjetivação. Por em contrapartida, encontramos modos de subjetivação que se expressam mais como subjetivações sujeitadas, enquanto que outros, expressam-se pela resistência ao enquadramento em determinado regime discursivo. Nesse sentido, as noções que darão sustentação para compreendermos o processo de subjetivação no ensino da filosofia serão de sujeição e resistência. (GELAMO, 2009)

Dito isto, é possível inferir que a produção de conhecimento ocorre de duas maneiras inseparáveis e imanentes no processo de ensino-aprendizagem. A primeira maneira ocorre como "consequência de uma sujeição, a partir de uma transmissão de conhecimentos implícitos no regime discursivo que se pretende verdadeira sobre o que deveria ser ensinado pelo professor e aprendido pelo aluno" (GELAMO, 2009, p. 148). Já o segundo aparece como resultado das relações de poder entre as sujeições e as resistências. É possível entender essas relações "como uma aprendizagem na experienciação que o aluno faz do contexto do ensino da filosofia (textos filosóficos, explicação do professor, discussão em sala de aula e construção do seu saber)" (GELAMO, 2009, p. 148).

Sendo assim podemos inferir em consonância com as reflexões de Gelamo (2009) que os saberes-aprendizagem que se configuram em momentos de resistência à sujeição não limitam-se as determinados conhecimentos que ocorrem por simples reprodução e repetição do pensamento dos filósofos, mas os absorvem sem privilegiar os lugares privilegiados da identidade do pensar. Logo, esses saberes-aprendizagem "que se produzem na resistência se diferenciam daqueles que são modelados nos processos de sujeição do pensamento, que têm como paradigma a sua validação nos modelos de pensamento trazidos pela história da filosofia" (GELAMO, 2009, p. 148).

Dito isto, a aprendizagem que se constrói como resistência são saberes singulares, que se constituem no processo do acontecimento do real. Por outro lado, os conhecimentos que emergem da construção da sujeição do pensamento, se produzem como formatação do modo de pensar dos estudantes a um molde pré-fabricado por uma tradição da verdade sobre o pensar. (GELAMO, 2009). Logo, ambos os processos são efeitos problematizadores 
provenientes das relações de poder e saber. Nesse ínterim, o tensionamento das forças permite ao estudante experimentar o ensino como resistência ao processo de transmissão de conteúdos manifestos pela propedêutica da explicação historiográfica do texto filosófico, pois por mais forte que seja os condicionantes da tradição e seus derivativos formativos, sempre haverá resistência nas relações de poder. Visto que em "toda a relação de poder implica, então, pelo menos de modo virtual, uma estratégia de luta" (FOUCAULT, 1995, p. 248).

Se analisarmos os desdobramentos dos problemas apresentados acima, veremos que tais questões nos afetam diretamente no que concerne nossas práticas didáticas e filosóficas, pois o enquadramento do estudante nas tradições filosóficas e a resistência como potência de pensamento que se inventa nesse processo pode ser um disparador para práticas de liberdade ou governo anátomo político dos corpos.

Ora, esta relação que ocorre entre a liberdade e governo disciplinar no processo de subjectivação exige não só uma contínua análise das práticas e das formas de racionalidade que com elas se articulam, como também um trabalho interrogativo sobre as estruturas que contribuem para a definição do sujeito: uma interrogação sobre o sujeito na sua relação com o saber, uma interrogação sobre o sujeito nas suas relações com o poder, uma interrogação sobre o sujeito na sua relação consigo mesmo.

\section{Considerações finais}

Se desconstruirmos a suposta linearidade existente entre Maugüé e Goldschmidt perceberemos dois processos ensino/aprendizagem distintos. O primeiro talvez pudesse estar mais próximo da noção de resistência, tendo em vista sua concepção de filosofar; o segundo funciona como um mecanismo de sujeição, principalmente pelo adestramento que esse sujeito sofre, pois, "antes de tentar filosofar, é preciso adquirir uma sólida formação historiográfica, conhecer bem os grandes autores (e alguns médio e outros pequenos...), domesticar os impulsos filosofantes, cuidar de adquirir método e rigor, etc" (PORCHAT PEREIRA, 2010, p. 28).

Sendo assim, os saberes-aprendizagem que se configuram a partir dos momentos de resistência à sujeição não se restringem ao processo de simples negação, ou de uma busca ingênua as disparidades do senso comum. Contudo, ao combater apenas a simples reprodução do pensamento historiográfico dos filósofos há uma nova perspectiva de apreensão do aprender e ensinar filosofia. As práticas de liberdade emergentes das resistências se diferenciam daqueles que são modelados nos processos de sujeição do pensamento. Consequentemente, não se abstém de toda riqueza oriunda dos modelos de pensamento trazidos pela história da Filosofia, mas percebem novas possibilidades de absorvê-las e reinventá-las através de um pensamento vivo no presente.

Dito isto a aprendizagem que se constrói como resistência emerge do processo de experienciação da realidade, para combater toda malha de poder estabelecida ao longo da nossa história para a sujeição do pensamento e adequação de um único modo de pensar pré-estabelecido. Porchat Pereira (2010), ao avaliar a formação dos professores 
do Departamento de Filosofia da USP, confessa que apesar das condições institucionais proporcionarem uma iniciação a prática filosófica, seus mestres apenas os preparam para que se tornassem bons historiadores da Filosofia. "E eles assim se tornaram, o que é muito bom. Mas foram educados - ou deseducados - no temor malsão da criatividade filosófica, o que foi muito mau. Sob esse aspecto, nós, os mestres deles, miseravelmente falhamos" (2010, p. 33)

A culpa tardia de Porchat serve de alerta as novas gerações que anseiam por uma construção filosófica que englobe todo avanço que os estudos historiográficos proporcionaram a formação filosófica brasileira, mas que desejam ultrapassar as barreiras dogmáticas do simples comentário de textos filosóficos.

\section{Agradecimentos}

Agradecemos à Coordenação de Aperfeiçoamento de Pessoal de Nível Superior (CAPES) pelo financiamento para a realização desta pesquisa.

\section{Referências}

ARANTES, Paulo Eduardo. Um departamento francês de ultramar. Estudos sobre a formação da cultura filosófica uspiana [Uma experiência nos anos 60]. São Paulo: Paz e Terra, 1994.

CORDEIRO, Denilson Soares. A formação do discernimento: Jean Maugüé a gênese de uma experiência filosófica no Brasil. 2008. 000 f. Tese (Doutorado) - Faculdade de Filosofia, Letras e Ciências Humanas. Departamento de Filosofia, Universidade de São Paulo, São Paulo, 2008.

CELESTE FILHO, Macioniro. A constituição da Universidade de São Paulo e a Reforma Universitária da década de 1960. São Paulo: Editora Unesp, 2013.

FOUCAULT, Michael. A arqueologia do saber. 8. ed. Rio de Janeiro: Forense Universitária, 2012.

FOUCAULT, Michel. A ordem do discurso. 3. ed. São Paulo: Edições Loyola, 1996.

FOUCAULT, Michel. Michel Foucault explica o seu último livro. In: FOUCAULT, Michael.

Ditos e escritos, vol. II. Rio de Janeiro: Forense Universitária. 2001, p. 145-152.

FOUCAULT, Michel. O sujeito e o poder. In: DREYFUS, H. L., RABINOW, P. Michel Foucault, uma trajetória filosófica: para além do estruturalismo e da hermenêutica. Rio de Janeiro: Forense Universitária, 1995.

GELAMO, Rodrigo Pelloso. O ensino da filosofia no limiar da contemporaneidade: o que faz o filósofo quando seu ofício é ser professor de filosofia? São Paulo: Cultura Acadêmica, 2009. 
GOLDSCHMIDT, Victor. Tempo lógico e tempo histórico na interpretação dos sistemas filosóficos. In: GOLDSCHMIDT, Victor. A religião de Platão. São Paulo: DIFEL, 1963.

KANT, Immanuel. Crítica da razão pura. São Paulo: Abril Cultural, 1983.

KANT, Immanuel. Ideia de uma história universal de um ponto de vista cosmopolita. São Paulo: Brasiliense, 1986.

MACHADO, Roberto. Foucault, a ciência e o saber. 3. ed. rev. e ampliada. Rio de Janeiro: Jorge Zahar Ed., 2006.

MARQUES, Ubirajara Rancan de Azevedo. História da filosofia no Brasil In: SILVA, Marcelo Carvalho da; CORNELLI, Gabriele. (Org.) . Filosofia e Formação - Vol. I. 1. ed. Cuiabá: Universidade Aberta do Brasil - Central de Texto, 2013.

MAUGÜÉ, Jean. O Ensino da Filosofia: suas diretrizes. Revista Brasileira de Filosofia, vol.V, fasc.IV, n. 20, out-dez 1955.

PORCHAT PEREIRA, Oswaldo. Discurso aos estudantes sobre a pesquisa em filosofia. Revista Fundamento, V. 1, n. 1 - set-dez. 2010.

ROUANET, Sergio Paulo; MERQUIOR, José Guilherme. Entrevista com Michel Foucault. In: O homem e o discurso: a arqueologia de Michel Foucault. $2^{\circ}$ ed. Rio de Janeiro: Tempo Brasileiro, 1996.

\section{Notas}

${ }^{1}$ Conferir ROUANET S, P; MERQUIOR J. G. Entrevista com Michel Foucault (1996).

${ }^{2}$ Adotamos a nomenclatura Faculdade de Filosofia, Ciências e Letras devido às singularidades discursivas existentes na criação da Universidade de São Paulo. A hipótese se funda na análise das modificações nas relações de saber e poder existentes na problematização da Reforma Universitária na década de 1960, ou seja, acreditamos que a nomenclatura adotada Faculdade de Filosofia, Letras e Ciências Humanas tenha sua emergência em uma nova rede discursiva de saber-poder. Algumas evidências podem ser encontradas no livro de Celeste Filho. A constituição da Universidade de São Paulo e a Reforma Universitária da década de 1960 (2013).

${ }^{3}$ Segundo Cordeiro (2008, p. 107) o programa de ensino elaborado Maugüé, "após as primeiras férias da Missão Francesa, largamente estabelecida de outubro de 1935 a fevereiro de 1936", era distinto da proposta curricular organizada e aplicada pelo seu antecessor Étienne Borne em 1934/35. Fundamento pelo conjunto de diretrizes, a nova grade curricular contemplariam os três anos do curso de Filosofia da seguinte maneira: $1^{\circ}$ Ano - Filosofia Geral, Psicologia e Sociologia; $2^{\circ}$ Ano - Filosofia Geral, História da Filosofia, Filosofia Moral e Social e Sociologia; $3^{\circ}$ Ano - Filosofia Geral, História da Filosofia, Filosofia Moral e Social e Sociologia.

${ }^{4}$ Para Foucault (2012, p. 140), o referencial "não é exatamente um fato, um estado de coisas, nem mesmo um objeto, mas um princípio de diferenciação".

${ }^{5}$ O sujeito, afirma Foucault (2012, p.140-141) não é "a consciência que fala, não o autor da formulação, mas uma posição que pode ser ocupada, sob certas condições, por indivíduos indiferentes".

${ }^{6}$ Segundo Foucault (2012, p.141) um campo associado "não é o contexto real da formulação, a situação na qual foi articular, mas um domínio de coexistência para outros enunciados".

${ }^{7}$ De acordo com Foucault (2012, p.141) uma materialidade "que não é apenas a substância ou o suporte da 
articulação, mas um status, regras de transcrição, possibilidades de uso ou de reutilização)

${ }^{8}$ Como podemos observar a formula "se ensina a filosofar" enunciada por Maugüé não condiz com o famoso adágio kantiano apresentado na Arquitetônica da razão, pois segundo Kant (1983, p. 407, B865) dentre "todas as ciências racionais (a priori), portanto, só é possível aprender Matemática, mas jamais Filosofia (a não ser historicamente); no que tange a razão, o máximo que se pode é aprender a filosofar". Desse modo, seria mais correto dizer que se aprende a filosofar e não como enuncia Maugüé, se Ensina a filosofar. É de extrema importância ressaltar que a adaptação elaborada por Maugüé, não condiz com as reflexões elaboradas por Kant na Arquitetônica da razão pura, especificamente as proposições kantianas sobre função da filosofia na formação do sujeito, pois Kant ao demarcar a impossibilidade de se ensinar a filosofia, enfatiza a autonomia do sujeito no aprender a filosofar

9 Vale observar que o modo como Maugüé apresenta o progresso está muito próximo daquilo que Kant compreende como progresso da história. Para isso, verificar a obra Ideia de uma história universal do ponto de vista cosmopolita de Kant.

${ }^{10}$ Conforme o próprio Foucault afirma no artigo O sujeito e o Poder de 1982, seu objetivo de trabalho não era analisar o poder, a sexualidade, a loucura, a prisão, mas "sobretudo produzir uma história os diferentes modos de subjetivação do ser humano em nossa cultura” (FOUCAULT, 1995, p. 1041-1042).

\section{Correspondência}

José Roberto Sanabria de Aleluia - Av. Dr. Hércules Galletti, 450, bloco 07, apto 403, Jardim Califórnia, CEP: 17527-350, Marília, Brasil.

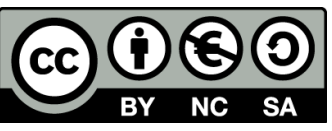

This work is licensed under a Creative Commons Attribution-NonCommercial 4.0 International (CC BY-NC 4.0) 